\title{
Concurrent Erythropoietin and Hypothermia Treatment Improve Outcomes in a Term Nonhuman Primate Model of Perinatal Asphyxia
}

\author{
Christopher M. Traudt ${ }^{a}$ Ronald J. McPherson ${ }^{a} \quad$ Larry A. Bauer $^{b}$ \\ Todd L. Richards ${ }^{c}$ Thomas M. Burbacher ${ }^{d}$ Ryan M. McAdams ${ }^{a}$ Sandra E. Juula \\ Departments of a Pediatrics, ${ }^{b}$ Pharmacy, ${ }^{c}$ Radiology and ${ }^{d}$ Environmental and Occupational Health Sciences, \\ University of Washington, Seattle, Wash., USA
}

\section{Key Words}

Hypoxic-ischemic encephalopathy - Spectroscopy .

Diffusion tensor imaging · Cerebellum · Pharmacokinetics .

Choline

\begin{abstract}
Background: Up to $65 \%$ of untreated infants suffering from moderate to severe hypoxic-ischemic encephalopathy (HIE) are at risk of death or major disability. Therapeutic hypothermia $(\mathrm{HT})$ reduces this risk to approximately 50\% (number needed to treat: 7-9). Erythropoietin (Epo) is a neuroprotective treatment that is promising as an adjunctive therapy to decrease HIE-induced injury because Epo decreases apoptosis, inflammation, and oxidative injury and promotes glial cell survival and angiogenesis. We hypothesized that HT and concurrent Epo will be safe and effective, improve survival, and reduce moderate-severe cerebral palsy (CP) in a term nonhuman primate model of perinatal asphyxia. Methodology: Thirty-five Macaca nemestrina were delivered after 1518 min of umbilical cord occlusion (UCO) and randomized to saline $(n=14)$, HT only $(n=9)$, or HT+Epo $(n=12)$. There were 12 unasphyxiated controls. Epo $(3,500 \mathrm{U} / \mathrm{kg} \times 1$ dose followed by 3 doses of 2,500 U/kg, or Epo 1,000 U/kg/day $\times 4$ doses) was given on days $1,2,3$, and 7 . Timed blood samples
\end{abstract}

were collected to measure plasma Epo concentrations. Animals underwent MRI/MRS and diffusion tensor imaging (DTI) at $<72 \mathrm{~h}$ of age and again at 9 months. A battery of weekly developmental assessments was performed. Results: UCO resulted in death or moderate-severe CP in $43 \%$ of saline-, $44 \%$ of HT-, and $0 \%$ of HT+Epo-treated animals. Compared to non-UCO control animals, UCO animals exhibit poor weight gain, behavioral impairment, poor cerebellar growth, and abnormal brain DTI. Compared to UCO saline, UCO HT+Epo improved motor and cognitive responses, cerebellar growth, and DTI measures and produced a death/ disability relative risk reduction of $0.911(95 \% \mathrm{Cl}-0.429$ to 0.994), an absolute risk reduction of $0.395(95 \% \mathrm{Cl} 0.072-$ $0.635)$, and a number needed to treat of 2 ( $95 \% \mathrm{Cl} 2-14)$. The effects of HT+Epo on DTI included an improved mode of anisotropy, fractional anisotropy, relative anisotropy, and volume ratio as compared to UCO saline-treated infants. No adverse drug reactions were noted in animals receiving Epo, and there were no hematology, liver, or kidney laboratory effects. Conclusions/Significance: HT+Epo treatment improved outcomes in nonhuman primates exposed to UCO. Adjunctive use of Epo combined with HT may improve the outcomes of term human infants with $\mathrm{HIE}$, and clinical trials are warranted.

(c) 2013 S. Karger AG, Basel

\section{KARGER}

E-Mail karger@karger.com

www.karger.com/dne
(C) 2013 S. Karger AG, Basel

0378-5866/13/0356-0491\$38.00/0
Sandra E. Juul

Department of Pediatrics, Division of Neonatology

Box 356320, HSB RR-542

Seattle, WA 98195 (USA)

E-Mail sjuul@u.washington.edu 


\section{Introduction}

Hypoxic-ischemic (HI) brain injury at birth remains a significant problem, affecting 1.3-1.7/1,000 term liveborn infants in the USA and contributing to $23 \%$ of neonatal deaths globally $[1,2]$. Untreated, moderate to severe HI encephalopathy (HIE) carries a $60-65 \%$ risk of either death or major neurodevelopmental disability, including mental retardation, cerebral palsy $(\mathrm{CP})$, hydrocephalus, and seizures $[3,4]$. Therapeutic hypothermia $(\mathrm{HT})$ in term infants reduces this risk to approximately $50 \%$, with a number needed to treat ranging from 7 to 9 [3]. The efficacy of HT provides proof of concept that HI brain injury can be mitigated; however, additional treatments are needed to further improve outcomes.

HIE evolves over more than a week [5-7]. Therapeutic HT targets early mechanisms of HI injury by reducing cerebral metabolism, excitotoxic neurotransmitter accumulation, ATP depletion, oxygen and nitrogen free radical release, and lipid peroxidation of cell membranes [810]. Ideally, supplementary HIE treatments will complement the mechanisms of HT neuroprotection [11, 12]. Erythropoietin (Epo) is a potentially promising supplemental therapy to augment brain repair and improve neurodevelopment outcomes. Small animal models of HIE have demonstrated that high-dose Epo treatment decreases neuronal apoptosis, oligodendrocyte injury, inflammation, oxidative injury, nitric oxide toxicity, and glutamate toxicity while increasing neurogenesis, oligodendrogenesis, glial cell proliferation, and angiogenesis $[13,14]$. We hypothesize that Epo+HT will be a safe and effective combination therapy that will improve survival and prevent the development of moderate-severe CP after HIE in a term nonhuman primate model of perinatal asphyxia [15].

\section{Methods}

\section{Animals}

The Animal Care and Use Committees at the University of Washington in accordance with US National Institutes of Health (NIH) guidelines approved all experimental protocols. Fifty-six Macaca nemestrina (pigtailed macaques) were delivered for the purposes of this study. Forty-two animals were delivered after umbilical cord occlusion (UCO) for either 15 or $18 \mathrm{~min}$. UCO subjects were assigned to 1 of 4 treatment groups: saline, Epo only, HT only, or HT+Epo. Nine animals of similar gestational age were delivered by cesarean section to serve as normal controls. The first 25 treatment assignments were simple randomization with the order of treatments determined by sorting a sequence of random numbers, and subsequent assignments followed adaptive randomization such that the sex of the animal at birth determined the treatment assignment until the groups were balanced; this was done in an effort to minimize gender effects [16]. Longitudinal neurodevelopment, anthropometric data, and spectroscopy data were also collected from concurrent controls $(n=5)$.

\section{Delivery and Resuscitation}

The use of UCO to model perinatal asphyxia in M. nemestrina has previously been reported and is summarized in figure $1[15,17]$. UCO was performed on animals in utero 1-8 days prior to term (173 days). The uterus was incised and the umbilical cord was externalized and clamped for 15 or $18 \mathrm{~min}$ (asphyxia group). While the clamp was in place, the uterus was supported with saline-soaked towels and an umbilical artery catheter was installed. After the UCO, the fetuses were delivered by hysterotomy. Control animals were also delivered by hysterotomy after intrauterine installation of an umbilical arterial catheter (2- to 3-min procedure). Fetuses were delivered and stabilized by a team of neonatologists using standardized neonatal resuscitation practice. Resuscitations included endotracheal intubation, positive pressure ventilation, chest compressions, and bolus epinephrine as indicated. Apgar scores were assigned at $1,5,10$, and $20 \mathrm{~min}$. Monitoring included a pulse oximeter, rectal thermometer, and amplitude-integrated EEG (aEEG) (BrainZ BRM3; Natus Medical Incorp., San Carlos, Calif., USA). A covered heating pad, radiant warmer, and polyethylene sheet were used to provide thermal support during stabilization, and then the animals were moved to a thermal-neutral incubator.

\section{Treatment Groups}

UCO animals were treated with saline, Epo, HT, or Epo+HT. Epo treatment was either 3,500 U/kg $\times 1$ dose i.v. followed by 3 i.v. doses of 2,500 U/kg given at $30 \mathrm{~min}, 24 \mathrm{~h}, 48 \mathrm{~h}$, and 7 days or Epo $1,000 \mathrm{U} / \mathrm{kg} /$ day i.v. $\times 4$ dosages at $30 \mathrm{~min}, 24 \mathrm{~h}, 48 \mathrm{~h}$, and 7 days (Epogen ${ }^{\circledR}$, epoetin alfa recombinant; Amgen) [15]. The initial Epo dosing was based on the 2,500 U/kg used in the phase I/II clinical trial [18] (with the addition of a 3,500-U/kg loading dose), but the dosing was lowered to $1,000 \mathrm{U} / \mathrm{kg}$ because the initial pharmacokinetics parameters were $25 \%$ higher than expected, possibly due to organ dysfunction or to HT. To produce HT, the animals were not actively warmed at delivery. Active cooling was begun after resuscitation of the infants and always occurred by the third hour of life. To maintain HT, a water blanket was applied to the animal's head and thermal support from the incubator was adjusted to achieve a rectal temperature of $33.5^{\circ} \mathrm{C}$ for $72 \mathrm{~h}$ (Olympic Medical Cool Care System; Olympic Medical, Seattle, Wash., USA). Rectal temperature was maintained by adjusting the incubator temperature. Rewarming was done slowly, raising the rectal temperature by $0.5^{\circ} \mathrm{C} / \mathrm{h}$.

\section{Animal Care}

Postresuscitation care was conducted as previously reported [15]. Briefly, arterial blood gas, lactate, and electrolytes (iSTAT ${ }^{\circledR}$; HESKA Corp., Loveland, Colo., USA) were measured at multiple, scheduled intervals. The study animals were maintained for a minimum of 3 days on parenteral fluids adjusted to maintain euglycemia and hydration. Enteral feedings were started on postnatal day 4, after rewarming for infants who were treated with HT, when the abdominal exam was normal and stooling was established. Weight was followed daily and standardized anthropometric measurements were done every week, including crown-rump length and head circumference. 


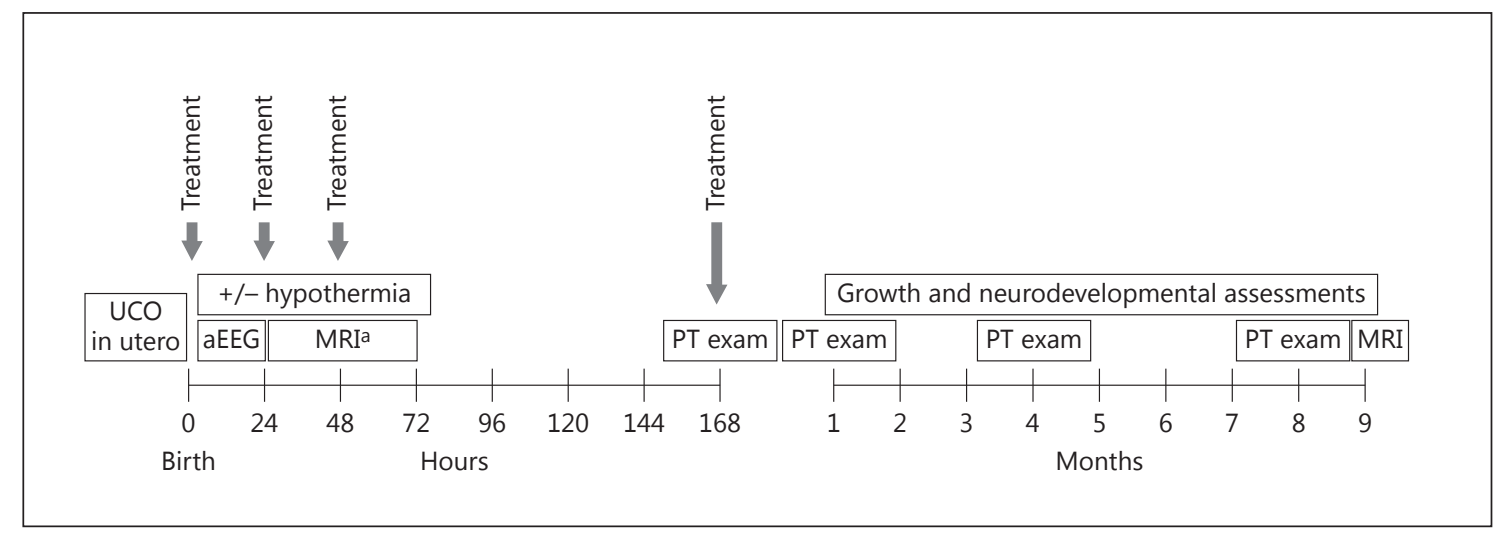

Fig. 1. Schedule of procedures and assessments for the nonhuman primate model of perinatal asphyxia. MRI = Magnetic resonance and diffusion tensor imaging and spectroscopy; PT = physical therapy. ${ }^{a}$ The first MRI scan was performed at either 24 or $72 \mathrm{~h}$ of age.

\section{Pharmacokinetic Analysis}

Blood samples $(0.1 \mathrm{ml} / \mathrm{sample})$ were collected to measure plasma Epo concentrations at timed intervals: 0 (predose baseline), $3,6,12,24,48$, and $72 \mathrm{~h}$ as previously described [18]. Data analysis was conducted using noncompartmental pharmacokinetic techniques. The trapezoidal rule was used to compute the area under the plasma concentration-versus-time curve (AUC) until the last measured value at $24 \mathrm{~h}$. The AUC was extended to infinity by taking the quotient of the 24-hour concentration and the elimination rate constant. $\mathrm{C}_{\max }$ is the maximum plasma concentration observed after the first dose.

The $t_{1 / 2}$ for the plasma Epo concentration-versus-time curve was computed by dividing 0.693 by the elimination rate constant. Clearance $(\mathrm{Cl})$, volume of distribution [using the steady-state $\left(\mathrm{V}_{\mathrm{ss}}\right)$ and area $\left(\mathrm{V}_{\text {area }}\right)$ methods], and mean residence time (MRT) were calculated using the following formulas: $\mathrm{Cl}=\mathrm{D} / \mathrm{AUC}, \mathrm{V}_{\mathrm{ss}}=(\mathrm{D} \times$ AUMC $) / A^{2} C^{2}, V_{\text {area }}=D /(k \times A U C)$, and $M R T=A U M C / A U C$, where $\mathrm{D}$ is the recombinant Epo dose and AUMC is the area under the first moment curve.

\section{Developmental Evaluations}

Developmental assessment was performed by the Infant Primate Research Laboratory at the University of Washington, as previously described [15]. Briefly, age at self-feeding and temperature stability, newborn reflexes, muscle tone, behavioral state, and neurological responses were assessed 5 days/week for the first 20 days using tests based on the Brazelton Neonatal Behavioral Assessment Scale. Neonatal activity was recorded every $4 \mathrm{~h}$. Evaluators who were blinded to treatment assigned an overall assessment of motor dysfunction. The object permanence testing paradigm, screening for deficits in visual acuity, novelty preference, social and motor behavior in mixed-sex play groups, and a standard series of learning and memory problems utilizing the Wisconsin General Test Apparatus were administered by trained evaluators.

To determine the presence or absence of $\mathrm{CP}$, animals were assessed by a physical therapist with a special interest in neonates. Sequential exams were done at 1 week, 1 month, and 8 months to document any evidence of motor abnormalities and contractures.
Assessment included evaluation of their ability to control active movement. Muscle tone at each joint was graded on the Ashford scale of 0 (normal) to 4 (affected parts rigid in flexion or extension) [19].

\section{MRI Acquisition and Analyses}

All surviving asphyxiated animals, control animals, and 5 colony animals underwent sedated MRI as previously described at 24 or $72 \mathrm{~h}$ and again at 9 months [15]. The total scan time was approximately $2 \mathrm{~h}$ and consisted of magnetization-prepared rapid gradient echo (MPRAGE) high-resolution T1-weighted imaging, diffusion tensor imaging (DTI), and single-voxel proton spectroscopy (MRS) acquired on a Philips Achieva 3.0 Tesla magnet with an X-series Quasar Dual gradient system. Two 8-channel array head coils were custom-made to fit neonatal and juvenile macaques. Details of the sequence acquisition were performed as previously reported [15].

Volumetric Analysis. Manual 3-D tracings of the whole brain, cerebellum, and caudate were created using the interactive semiautomated tools within RView software (http://rview.colin-studholme.net/), and the corresponding volumes were calculated [20]. Tracings were performed by 3 separate observers who were blind to the treatment. Specific boundaries for total brain, caudate, and cerebellum were defined. The total brain volume included the cerebral hemispheres, superior sagittal sinus, diencephalon, brainstem, and cerebellum. The ventricular and extraaxial cerebrospinal fluid, optic chiasm, and pituitary stalk were excluded, and the brainstem was truncated at the foramen magnum. The cerebellum was outlined separately with the peduncles and brainstem excluded. Individuals masked to treatment group and outcome performed outlining in duplicate. The interrater reliability of brain segmentation was determined by Dice similarity coefficients. The Dice similarity coefficients between the 3 tracers ranged from 0.885 to 0.921 for caudate, 0.9255 to 0.9862 for cerebellum, and 0.9135 to 0.9738 for cortex. Final images were rendered in 3-D and inspected for accuracy before structural volumes were computed.

DTI. Voxelwise statistical analysis of the fractional anisotropy (FA) data was carried out using tract-based spatial statistics [21] 
(TBSS), part of the FMRIB Software Library (FSL) [22]. First, FA images were created by fitting a tensor model to the raw diffusion data using FDT, and they were then brain-extracted using BET [23]. All subjects' FA data were then aligned into a common space using the nonlinear registration tool FNIRT $[24,25]$, which uses a b-spline representation of the registration warp field [26]. Representative control animal scans at 3 days and 9 months were used to align animals instead of the human normal space. Next, the mean FA image was created and thinned to create a mean FA skeleton, which represents the centers of all tracts common to the group. Each subject's aligned FA data were then projected onto this skeleton, and the resulting data were fed into voxelwise crosssubject statistics. Voxelwise cross-subject statistics on non-FA DTI data (first eigenvalue, second eigenvalue, third eigenvalue, relative anisotropy, mean diffusivity, mode of anisotropy, volume ratio, radial diffusivity, and raw T2 signal without diffusion weighting) were performed using the tbss_non_FA command. Thresholdfree cluster enhancement with correction for multiple comparison results was used to determine significance.

MR Spectroscopy. Single-voxel MRS was acquired using the point-resolved spectroscopy (PRESS) pulse sequence centered on a $10 \times 10 \times 10-\mathrm{mm}$ voxel on the right thalamus in order to calculate the absolute concentrations of $\mathrm{N}$-acetyl aspartate, creatine, choline, myo-inositol, glycine, glutamate, and glutamine as previously described using LCModel $[15,27,28]$.

TE Phase Lactate. Lactate was analyzed separately from the other brain metabolites in order to isolate it from macromolecules/ proteins as previously described [15].

J-Resolved Spectroscopy. For each subject, a 2-D J-resolved acquisition sequence was acquired from a $2 \times 2 \times 2-\mathrm{cm}$ voxel centered on the thalamus as previously described [15]. Custom software was used to perform a 2-D Fourier transform and then the resulting signals were combined with LCModel to estimate metabolite concentrations. With software called GAVA (www. briansoher.com), simulated JRES data were used to find the exact position of the J-coupled metabolites gamma-aminobutyric acid (GABA) and glutamine. Gaussian filter adjustments were made to maximize the separation of each metabolite.

\section{Statistics}

DTI was compared by voxelwise statistical analysis and can compare only 2 groups at once [21]. Levene's test evaluated homogeneity. Parametric comparisons are presented as means with standard error (SEM) and numbers of animals. All comparisons were two-tailed, with $\alpha \leq 0.05$. Two analyses were conducted. First, validation that the model produces injury was determined by comparing control animals to any animal that received UCO. Second, determination of the neuroprotection of treatments was performed with the exclusion of the control group. Post hoc testing of treatment effects was compared to UCO saline as the control group. Death or moderate-severe CP and epinephrine, sodium bicarbonate, and phenobarbital administration were evaluated by cross-tabs with the binary output as the row and asphyxia (yes or no) as one column (Pearson's $\chi^{2}$ ) and treatment (saline, HT, and HT+Epo) as the other column (Fisher's exact test) using SPSS (SPSS Inc., Chicago, Ill., USA). All other comparisons were made using univariate ANOVA analysis with fixed factors of asphyxia (yes or no) and treatment (saline, HT, and HT+Epo) with appropriate post hoc comparisons to UCO saline using SPSS.

\section{Results}

Fifty-six $M$. nemestrina nonhuman primates were included in this study. Forty-two were delivered after UCO for either $15(\mathrm{n}=19)$ or $18 \mathrm{~min}(\mathrm{n}=23)$ and randomized to: saline $(n=14)$, Epo $(n=6)$, HT $(n=10)$, or HT+Epo $(\mathrm{n}=12)$. Controls $(\mathrm{n}=14$ total) included age-matched surgically delivered animals $(n=9)$ and concurrent colony controls $(\mathrm{n}=5)$. Two of the 6 Epo-only-treated animals were disqualified: 1 due to a difficult resuscitation with prolonged hypoxia, and 1 due to a cardiac arrest while undergoing MRI. During the study period, HT became the clinical standard of care in humans. No further animals were enrolled in the Epo-only group, which excluded this group from analysis due to low numbers. Three additional animals were excluded from the final analysis: 1 animal randomized to HT (could not be resuscitated at birth) and 2 control animals (1 required intubation at birth with evidence of intrauterine compromise [29], and 1 had unexpected idiopathic hydrocephalus by MRI).

Of the 35 asphyxiated animals included in the analysis, 5 (14\%) died prior to the planned necropsy, with deaths distributed by treatment as shown in figure 2 . Three deaths occurred early ( 2 were euthanized at 3 days of age, and 1 at 6 days of age for severe neurological compromise), and 2 were due to late complications ( 1 died due to aspiration pneumonia, and 1 died unexpectedly at 5 months after unexplained tachypnea since the first week of age). Three deaths were in animals exposed to $15 \mathrm{~min}$ of UCO, and 2 were in animals exposed to $18 \mathrm{~min}$ of UCO. The gestational age of the study animals at birth was not different between controls and UCO animals $(169 \pm 1$ vs. $168 \pm 1$ days, $\mathrm{p}=0.34)$. Birth weight $(547 \pm$ 16 vs. $547 \pm 13 \mathrm{~g}, \mathrm{p}=0.99)$, head circumference (20.6 \pm 0.2 vs. $20.5 \pm 0.1 \mathrm{~cm}, \mathrm{p}=0.57$, and crown-rump length $20.6 \pm 0.2$ vs. $20.3 \pm 0.1 \mathrm{~cm}, \mathrm{p}=0.28$ ) were not different between groups. Epinephrine was given in 32\% of resuscitations, and $20 \%$ of animals received sodium bicarbonate in the first $3 \mathrm{~h}$ after birth. The initial neurologic exam of all UCO animals prior to study treatments was profoundly abnormal, with no spontaneous respirations or movement, no withdrawal to painful stimuli, and flaccidity. All UCO animals required intubation and mechanical ventilation before study treatments were administered. UCO animals differed from controls in initial pH (6.94 \pm 0.03 vs. $7.19 \pm 0.04, \mathrm{p}<0.001)$, base deficit $(19.4 \pm 0.7$ vs. $9.3 \pm 1.3, \mathrm{p}<0.001)$, and serum lactate $(13.2 \pm 0.4$ vs. 5.9 $\pm 0.9, \mathrm{p}<0.001)$. The Apgar scores in animals with UCO of 0,15 , and $18 \mathrm{~min}$ are shown in figure 3 . An early aEEG
Traudt/McPherson/Bauer/Richards/ Burbacher/McAdams/Juul 
in all UCO animals was consistent with the obtunded physical exam, with lower margins generally $<2 \mu \mathrm{V}$, upper margins $<10 \mu \mathrm{V}$, and a burst suppression pattern. A slow improvement in voltage occurred over the first $6 \mathrm{~h}$ of life. Phenobarbital was given to $49 \%$ of UCO infants for documented clinical seizures (7 UCO saline, $5 \mathrm{HT}$, and 5 HT+Epo; Pearson's $\chi^{2}, \mathrm{p}=0.81$ ).

\section{Growth}

Figure 4 illustrates the daily weights of animals over 38 postnatal weeks to show that the average weights for UCO-exposed animals remained below the 50th percentile compared to control animals despite adjustments to the caloric density of formula (up to $24 \mathrm{kcal} /$ ounce) to foster weight gain. The inset in figure 4 is a comparison of the mean time to regain birth weight and shows that this time was increased for both the UCO saline and the UCO HT groups. UCO was associated with a decreased head circumference growth rate $(\mathrm{p}<0.05)$, and this parameter improved with all treatments (data not shown).

\section{Behavioral Results}

UCO was associated with delayed achievement of early developmental milestones, including the ability to regulate temperature, as reflected by the number of days required to wean from an incubator and maintain euthermia without a heating pad (table 1). UCO also delayed the animals' ability to feed themselves (table 1). The time to resolution of primitive reflexes (rooting, righting, snout, sucking, and placing) was also delayed by UCO (table 1). Study treatments did not significantly affect these parameters; however, infants treated with $\mathrm{HT}+\mathrm{EPO}$ trended towards improved scores. Compared to controls, UCO animals exhibited delays in multiple behavioral indices including the capacity to: sit, stand, walk, climb, and climb off a diaper roll (MRT); leave the security of their 'sleep diaper' in order to explore the playroom (diaper trip); release their grasp and explore when challenged to hang from a support (release grasp); touch another animal (initiate contact), and climb up a chain (table 2). Concurrent $\mathrm{HT}+$ Epo treatment significantly decreased the age at which infants reached for a toy, exhibited hand-overhand chain climbing (table 2) and object permanence (table 3) compared to UCO saline-treated infants.

The visual paired-comparison test methodology was used to study emerging recognition memory skills in the first months of postnatal life [for review, see 30]. On problems using simple geometric forms, UCO saline infants performed poorly, while infants receiving $\mathrm{HT}+$ Epo provided significant evidence of recognition memory $(\mathrm{p}<$

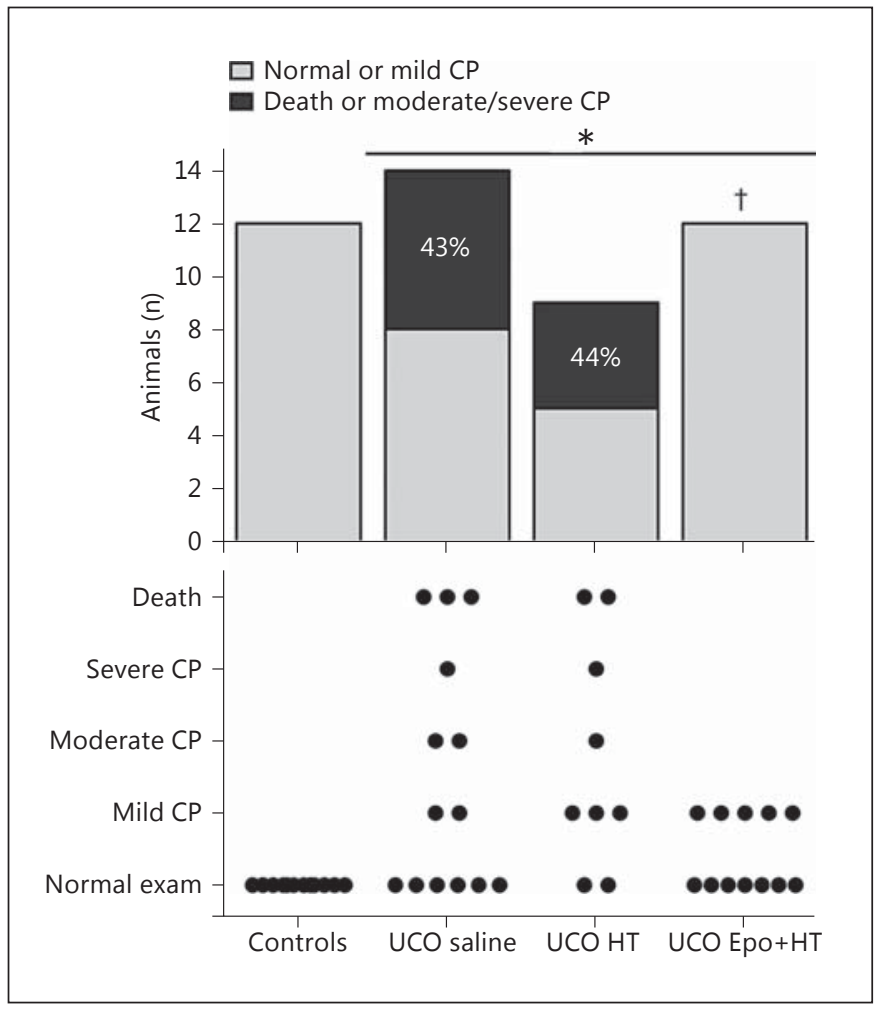

Fig. 2. Death or severity of CP after UCO. Number of animals with death or moderate/severe CP (top). Individual severity scores for all animals by treatment group (bottom). The severity of CP was based upon 4 physical therapy exams performed at 1 week and at 1,4 , and 8 months of age. UCO increased the rate of death or moderate/severe CP as compared to controls (Pearson's $\chi 2 * \mathrm{p}<0.05$ ). Treatment with HT+Epo improved outcomes (Dunnett's test, ${ }^{\dagger} \mathrm{p}$ $<0.05)$.

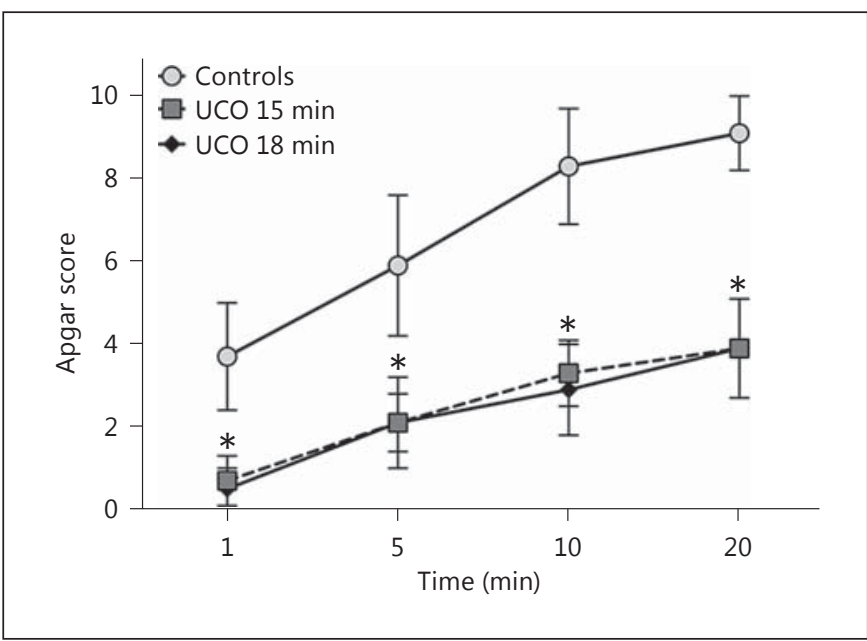

Fig. 3. Initial response to UCO. Data are mean $( \pm$ SEM $)$ Apgar scores for neonatal animals separated by the duration of UCO (Pearson's $\left.\chi^{*} \mathrm{p}<0.05\right)$. 
Table 1. Neonatal behavioral measures

\begin{tabular}{lcccrr}
\hline Index & Controls & UCO all & UCO saline & UCO HT & UCO HT+Epo \\
\hline Animals, $n$ & 12 & 32 & 12 & 8 & 12 \\
Out of the incubator & $5.4 \pm 0.4$ & $9.7 \pm 0.8^{*}$ & $11.0 \pm 2.2$ & $9.6 \pm 0.5$ & $15 \pm 0.4$ \\
Off the heating pad & $11.8 \pm 0.4$ & $16.1 \pm 1.0^{*}$ & $17.7 \pm 2.5$ & $15.6 \pm 0.8$ & $183.0 \pm 0.8$ \\
Self-feeding & $12.7 \pm 0.6$ & $23.3 \pm 2.7^{*}$ & $27.6 \pm 4.0$ & $28.5 \pm 8.6$ & $16.5 \pm 0.8$ \\
Primitive reflexes & $2.5 \pm 1.6$ & $5.7 \pm 0.7^{*}$ & $7.4 \pm 1.1$ & $5.5 \pm 1.5$ & $4.1 \pm 0.7$ \\
\hline
\end{tabular}

Data are the mean age $( \pm$ SEM $)$ at which a task was successfully performed for each separate treatment group unless otherwise stated. Significant ANOVA post hoc tests are indicated as $* \mathrm{p}<0.05$ compared to controls.

Table 2. Developmental behavioral measures

\begin{tabular}{|c|c|c|c|c|c|}
\hline Animals, $\mathrm{n}$ & 12 & 32 & 12 & 8 & 12 \\
\hline Diaper trip & $18.2 \pm 2.1$ & $23.3 \pm 1.7^{*}$ & $27.1 \pm 2.1$ & $22.4 \pm 4.5$ & $20.1 \pm 2.3$ \\
\hline Release grasp & $41.5 \pm 4.0$ & $54.2 \pm 6.3^{*}$ & $67.2 \pm 9.1$ & $59.4 \pm 19.4$ & $37.8 \pm 3.4$ \\
\hline Initiate contact & $19.1 \pm 2.4$ & $25.8 \pm 1.7^{*}$ & $28.3 \pm 2.4$ & $25.4 \pm 4.6$ & $23.5 \pm 2.4$ \\
\hline Reach for a toy & $27.3 \pm 2.9$ & $29.5 \pm 1.9$ & $34.3 \pm 2.9$ & $31.4 \pm 4.1$ & $23.6 \pm 2.3^{\dagger}$ \\
\hline
\end{tabular}

Data are the mean age $( \pm$ SEM $)$ at which a task was successfully performed for each separate treatment group.

Significant ANOVA post hoc tests are indicated as ${ }^{*} \mathrm{p}<0.05$ compared to controls, and ${ }^{\dagger} \mathrm{p}<0.05$ compared to UCO saline.

Table 3. Object permanence

\begin{tabular}{lccccc}
\hline Index & Controls & UCO all & UCO saline & UCO HT & UCO HT+Epo \\
\hline Animals, $n$ & 12 & 32 & 12 & 8 & 12 \\
No screen & $35.8 \pm 2.8$ & $39.4 \pm 1.9^{*}$ & $45.3 \pm 2.5$ & $38.4 \pm 4.1$ & $34.3 \pm 3.0^{\dagger}$ \\
With screen & $36.2 \pm 2.8$ & $42.1 \pm 2.3^{*}$ & $47.3 \pm 2.3$ & $41.8 \pm 6.3$ & $37.1 \pm 3.8$ \\
Item in well & $38.3 \pm 2.5$ & $40.4 \pm 2.2$ & $47.1 \pm 2.8$ & $38.9 \pm 4.1$ & $34.7 \pm 3.8^{\dagger}$ \\
\hline
\end{tabular}

Data are the mean age $( \pm$ SEM $)$ at which a hidden object was recognized for each separate treatment group.

Significant ANOVA post hoc tests are indicated as ${ }^{*} \mathrm{p}<0.05$ compared to controls, and ${ }^{\dagger} \mathrm{p}<0.05$ compared to UCO saline.

0.05). This finding suggests a disruption in the early memory processing of UCO infants, but also a sparing of some adverse memory effects in animals receiving treatment. When more challenging test problems were administered, both UCO saline and treated animals failed to provide evidence of memory when compared to control infants. Analysis of overall performance across experimental groups, independent of problem difficulty, revealed that the highest memory scores were observed in control and $\mathrm{HT}+$ Epo infants $(\mathrm{p}<0.0001)$. Animals in the HT treatment group were able to provide some evidence of memory on this task ( $\mathrm{p}<0.05)$, but control and HT+Epo infants provided the strongest psychometric profile on this early measure of cognition and information processing. 


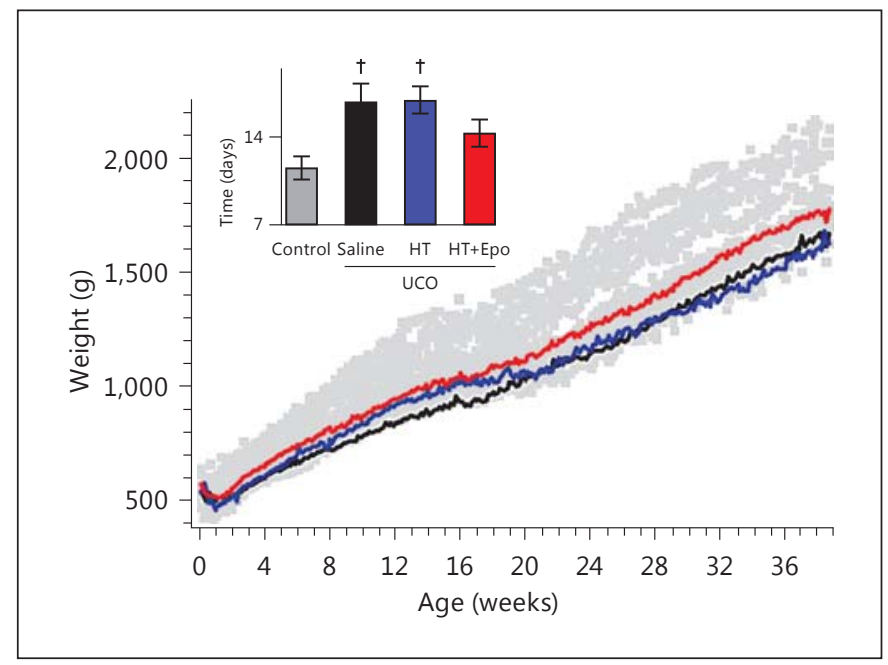

Fig. 4. Longitudinal growth of nonhuman primates. The main graph plots the average weight of UCO-exposed animals (lines) superimposed upon the individual daily weights of control animals (squares), with an inset graph plotting the mean $( \pm$ SEM) days to regain birth weight. The mean daily weights for the UCO saline (black line), UCO HT (blue line), and UCO HT+Epo (red line) groups are shown separately. The inset shows that the time to regain birth weight was significantly elevated for UCO saline and UCO HT animals (Dunnett's test, ${ }^{\dagger} \mathrm{p}<0.01$ ). These graphs illustrate that UCO reduces the growth of animals despite caloric adjustments to foster weight gain.

\section{MRI and Spectroscopy}

No significant effects of UCO or treatment were detected on gross brain structure evaluated either early (days $1-3$ ) or late (6 or 9 months). To evaluate brain growth, brain volume at 9 months was compared to brain volume within $72 \mathrm{~h}$ of birth ( $\mathrm{n}=35,7$ controls, $9 \mathrm{UCO}$ saline, $6 \mathrm{HT}$, and $8 \mathrm{HT}+\mathrm{Epo})$. There were no effects of $\mathrm{UCO}$ on total brain, cortical, or basal ganglia volumes. In contrast, cerebellar volume was decreased by UCO compared to controls, and combined HT+Epo treatment improved cerebellar growth after UCO (fig. 5). There were no left-right differences in brain volumes or specific MRI lesions among the study groups.

We used FA to evaluate fiber density, axonal diameter, and myelination. FSL tract-based spatial statistics revealed changes in the mode of anisotropy between UCO saline and control animals (fig. 6) [31]. FA, relative anisotropy (fig. 6), and volume ratio differences between $\mathrm{HT}+\mathrm{Epo}$ and UCO saline were detected in animals scanned at $72 \mathrm{~h}$. At 9 months, the raw T2 signal was increased in injured animals, with UCO saline animals having the highest signal and controls the lowest signal (fig. 4). In animals that underwent UCO for $18 \mathrm{~min}$, ear-

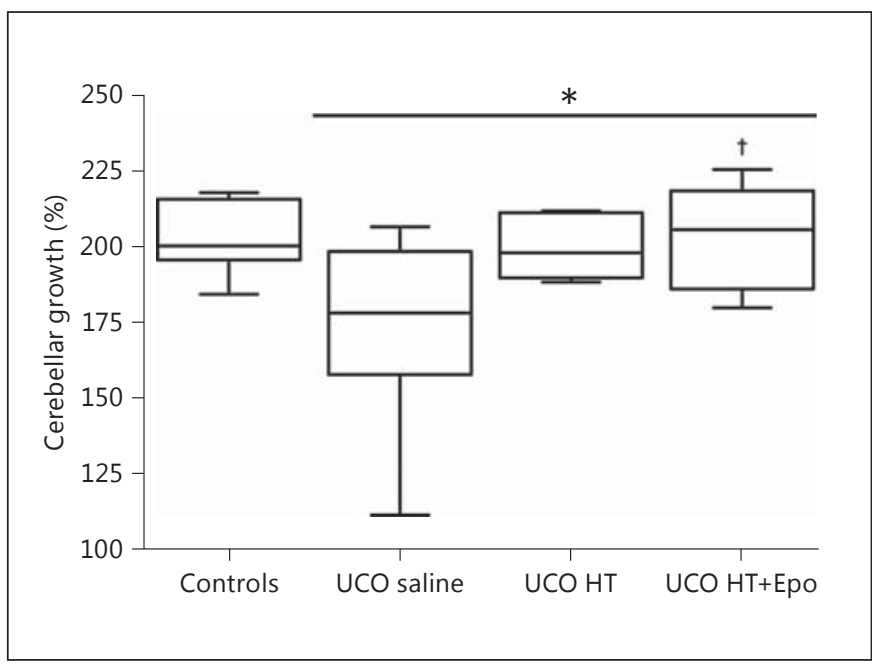

Fig. 5. Cerebellar growth from birth to 9 months of age. Box-andwhisker plots (median and quartile range) illustrate the percentage increase in cerebellar volume for animals in each treatment group. Cerebellar growth was decreased by UCO compared to controls. Significant differences are indicated (ANOVA, ${ }^{*} \mathrm{p} \leq$ 0.05). Treatment with HT+Epo is associated with improved growth after UCO when compared to UCO saline-treated animals (Dunnett's test, ${ }^{\dagger} \mathrm{p}=0.019, \mathrm{n}=9 \mathrm{UCO}$ saline, $\mathrm{n}=6 \mathrm{UCO}$ HT, and $\mathrm{n}=8$ UCO HT+Epo).

ly scans ( 24 and $72 \mathrm{~h}$ ) of HT+Epo animals showed improved FA, relative anisotropy, and improved volume ratios compared to UCO saline animals (fig. 7). The mode of anisotropy differentiated between UCO saline and $\mathrm{HT}+$ Epo animals within the first $72 \mathrm{~h}$ after a UCO duration of $18 \mathrm{~min}$. At 9 months, the raw T2 signal was similar to the combined 15- and 18-min UCO results.

Spectroscopy results are shown in table 4 . The $\mathrm{N}$-acetyl aspartate (NAA)/creatine ratio in the first $72 \mathrm{~h}$ and the GABA level at 9 months were altered by UCO. While the GABA levels decreased with treatment, this change was not statistically significant. Treatment did affect the choline level and the choline/creatine, NAA/choline, and $\mathrm{NAA}$ /creatine ratios so that animals treated with $\mathrm{HT}+\mathrm{Epo}$ demonstrated improved values. Choline levels correlated with death or moderate-severe CP in animals that underwent UCO (Pearson's correlation 0.375, $\mathrm{p}=0.029, \mathrm{n}=$ 34). Analysis of phosphorus data did not reveal any effects of UCO or treatment. However, the overall energy available to cells increased (as measured by lower inorganic phosphorus levels) to control values over time in the HT and $\mathrm{HT}+$ Epo groups. 
Fig. 6. DTI after UCO. TBSS analysis of mode of anisotropy, relative anisotropy, and raw T2 signal maps with red indicating areas that had an increased signal compared to UCO saline and blue areas indicating lower signals. Highlighted (red or blue) regions, $\mathrm{p} \leq 0.05$ using threshold-free cluster enhancement with correction for multiple comparisons. Higher values of mode of anisotropy and relative anisotropy are associated with healthy white matter. Lower values of T2 signal are associated with healthy white matter. Top and middle: validation of the perinatal asphyxia model; bottom: demonstration that HT+Epo improves DTI.

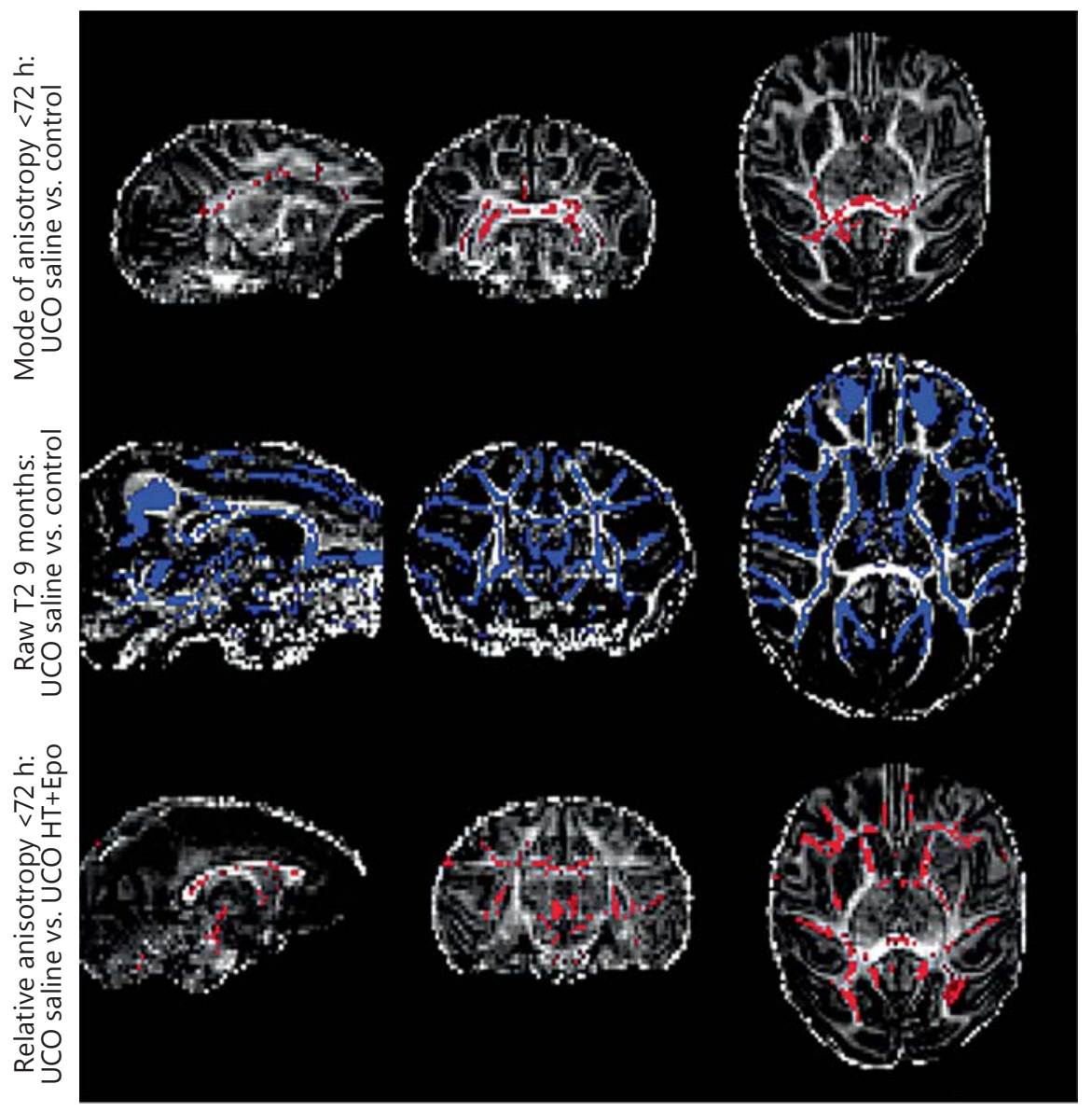

Table 4. MRS findings

\begin{tabular}{|c|c|c|c|c|c|}
\hline & Controls & UCO all & UCO saline & UCO HT & UCO HT+Epo \\
\hline \multicolumn{6}{|l|}{ First $72 \mathrm{~h}$} \\
\hline Animals, $\mathrm{n}$ & $8-12$ & $27-34$ & $11-13$ & $7-9$ & $9-12$ \\
\hline Choline/creatine & $0.29 \pm 0.01$ & $0.27 \pm 0.01$ & $0.30 \pm 0.01$ & $0.26 \pm 0.01^{\dagger}$ & $0.25 \pm 0.01^{\dagger}$ \\
\hline NAA/choline & $2.79 \pm 0.08$ & $2.79 \pm 0.09$ & $2.50 \pm 0.13$ & $2.81 \pm 0.12$ & $3.13 \pm 0.11^{\dagger}$ \\
\hline NAA/creatine & $0.79 \pm 0.02$ & $0.74 \pm 0.01^{*}$ & $0.73 \pm 0.02$ & $0.72 \pm 0.03$ & $0.78 \pm 0.02$ \\
\hline Animals, $\mathrm{n}$ & 8 & 24 & 9 & 6 & 9 \\
\hline $\mathrm{GABA}, \mathrm{mm} / \mathrm{kg}$ & $0.91 \pm 0.08$ & $0.76 \pm 0.04^{*}$ & $0.67 \pm 0.08$ & $0.80 \pm 0.05$ & $0.82 \pm 0.08$ \\
\hline
\end{tabular}

Data are mean $( \pm$ SEM) values determined by MRS at two different ages separated by treatment group.

Significant ANOVA post hoc tests are indicated as ${ }^{*} \mathrm{p}<0.05$ compared to controls, and ${ }^{\dagger} \mathrm{p}<0.05$ compared to UCO saline.

\section{Safety Parameters}

Blood urea nitrogen levels were elevated $24 \mathrm{~h}$ after UCO compared to controls ( $20.7 \pm 1.0$ vs. $16.3 \pm 2.4 \mathrm{mg} /$ $\mathrm{dl})$, but this did not persist, and no treatment effects were noted. Serum creatinine levels were not different between control and UCO animals. Animals undergoing HT therapy had lower serum creatinine values at $24 \mathrm{~h}$ than did infants receiving UCO saline (UCO saline $1.20 \pm 0.07 \mathrm{mg}$ / $\mathrm{dl}$; HT $0.96 \pm 0.06 \mathrm{mg} / \mathrm{dl}, \mathrm{p}=0.071 ; \mathrm{HT}+$ Epo $0.92 \pm 0.08$ $\mathrm{mg} / \mathrm{dl}, \mathrm{p}=0.017$ ). Liver function tests (aspartate amino- 
Fig. 7. DTI after $18 \mathrm{~min}$ of UCO. TBSS analysis of FA, relative anisotropy (RA), and volume ratio (VR) between UCO saline and HT+Epo after $18 \mathrm{~min}$ of $\mathrm{UCO}$ is shown. DTI scans occurred within the first $72 \mathrm{~h}$. Red areas indicate where the HT+Epo group had higher values than the UCO saline group, while blue signifies lower values in the HT+Epo group. Highlighted regions (red or blue), $\mathrm{p} \leq 0.05$ using threshold-free cluster enhancement with correction for multiple comparisons. Colors are visible online only. Higher values of FA and relative anisotropy are indicative of healthy white matter. Lower values of volume ratio are indicative of healthy white matter.

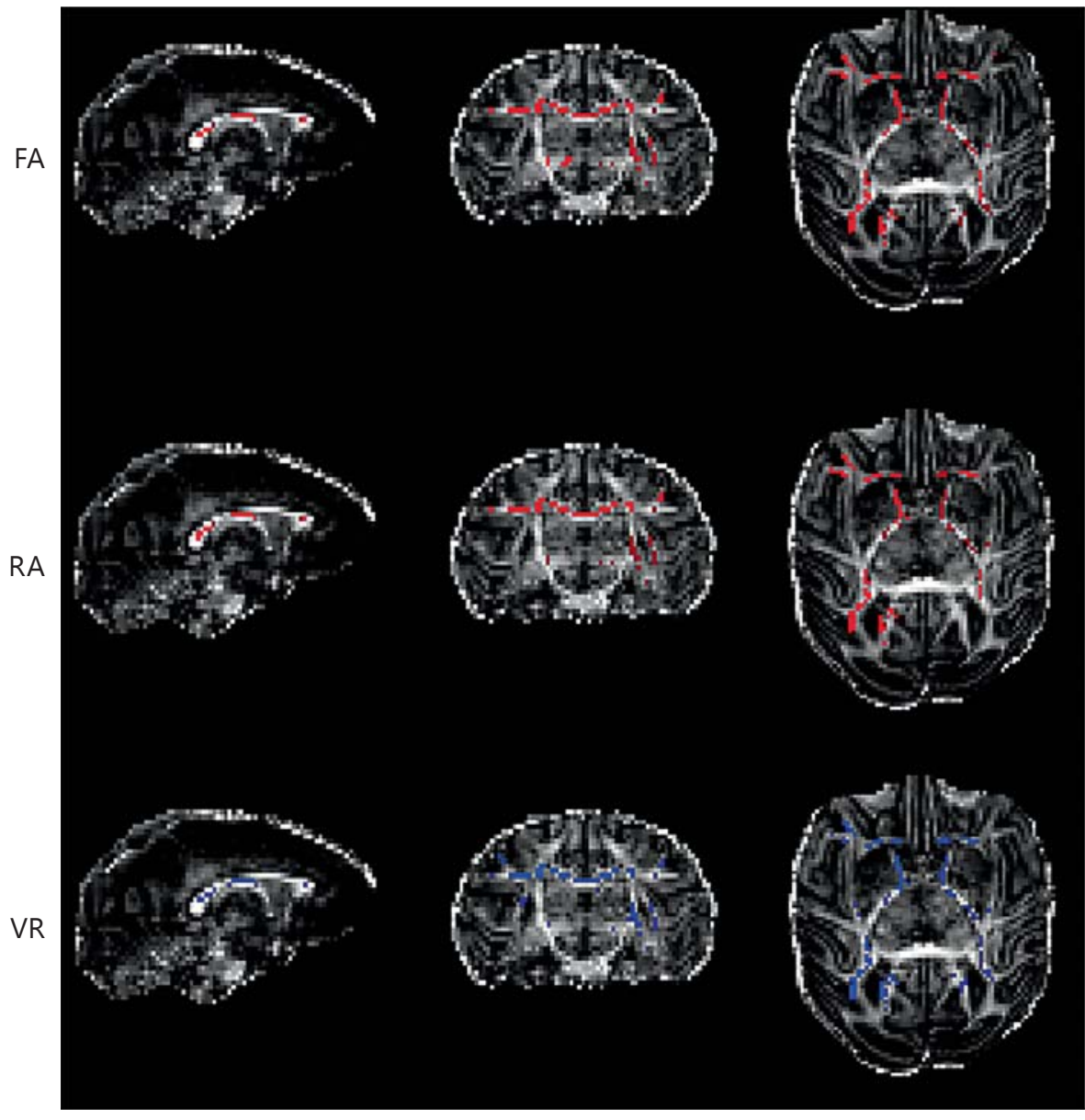

transferase, alanine aminotransferase, serum bilirubin, and cholesterol) did not differ at any time point. Although not affected by treatment, white blood cell counts were decreased in UCO infants compared to control animals at 1 week of age $(8.2 \pm 1.1 \times 1,000 / \mu \mathrm{l}$ vs. $5.1 \pm 0.3 \times 1,000 /$ $\mu \mathrm{l}, \mathrm{p}=0.003$ ) but not at any other time point (table 5). Hematocrit and platelet counts were unchanged by UCO or treatment group at any time point (table 5).

\section{Epo Pharmacokinetics}

The peak Epo concentration $\left(\mathrm{C}_{\max }\right)$ for animals receiving 3,500 U/kg Epo+HT was 60,996 $\pm 25,635 \mathrm{mU} / \mathrm{ml}$ $(\mathrm{n}=6)$ compared to $16,290 \pm 3,678 \mathrm{mU} / \mathrm{ml}$ for those who received 1,000 U/kg Epo+HT $(\mathrm{n}=4)$. Note that insufficient samples were available from some animals to conduct a complete pharmacokinetic analysis and that one of the higher-dose infants received 3,000 U/kg due to a dosage administration error. Of the 4 animals receiving 1,000 $\mathrm{U} / \mathrm{kg}, 3 \mathrm{had}$ no $\mathrm{CP}$ and 1 had mild CP. Of the 6 receiving
Table 5. Complete blood count results

\begin{tabular}{ccccll}
\hline Age, days & Control & UCO all & $\begin{array}{l}\text { UCO } \\
\text { saline }\end{array}$ & $\begin{array}{l}\text { UCO } \\
\text { HT }\end{array}$ & $\begin{array}{l}\text { UCO } \\
\text { HT+Epo }\end{array}$ \\
\hline \multicolumn{7}{l}{ Hematocrit, \% } \\
1 & $40.5 \pm 1.4$ & $42.4 \pm 0.9$ & $44.0 \pm 1.3$ & $41.1 \pm 2.0$ & $42.9 \pm 1.5$ \\
7 & $35.0 \pm 1.3$ & $37.3 \pm 0.8$ & $37.1 \pm 1.2$ & $36.2 \pm 1.0$ & $38.4 \pm 1.5$ \\
270 & $41.0 \pm 1.3$ & $40.4 \pm 0.4$ & $40.4 \pm 0.7$ & $40.5 \pm 0.8$ & $40.1 \pm 0.6$ \\
Platelet count, $\times 1,000 / \mu l$ & & & & \\
1 & $360 \pm 31$ & $326 \pm 13$ & $333 \pm 26$ & $295 \pm 25$ & $353 \pm 26$ \\
7 & $512 \pm 36$ & $477 \pm 28$ & $501 \pm 65$ & $419 \pm 25$ & $498 \pm 24$ \\
270 & $500 \pm 22$ & $462 \pm 20$ & $495 \pm 33$ & $404 \pm 37$ & $451 \pm 38$ \\
White blood cell count, $\times 1,000 / \mu l$ & & & \\
1 & $7.6 \pm 1.3$ & $6.7 \pm 0.4$ & $7.5 \pm 0.4$ & $5.8 \pm 0.8$ & $7.0 \pm 0.7$ \\
7 & $8.2 \pm 1.1$ & $5.1 \pm 0.3 *$ & $5.2 \pm 0.5$ & $4.0 \pm 1.2$ & $5.6 \pm 0.3$ \\
270 & $7.3 \pm 1.2$ & $5.8 \pm 0.5$ & $5.8 \pm 0.6$ & $6.0 \pm 1.7$ & $4.9 \pm 0.3$ \\
\hline
\end{tabular}

Data are the mean values $( \pm$ SEM $)$ of laboratory measures for separate treatment groups. UCO significantly lowered the white blood cell counts on day 7 compared to controls as indicated (ANOVA, $\left.{ }^{*} \mathrm{p}<0.05\right)$. 

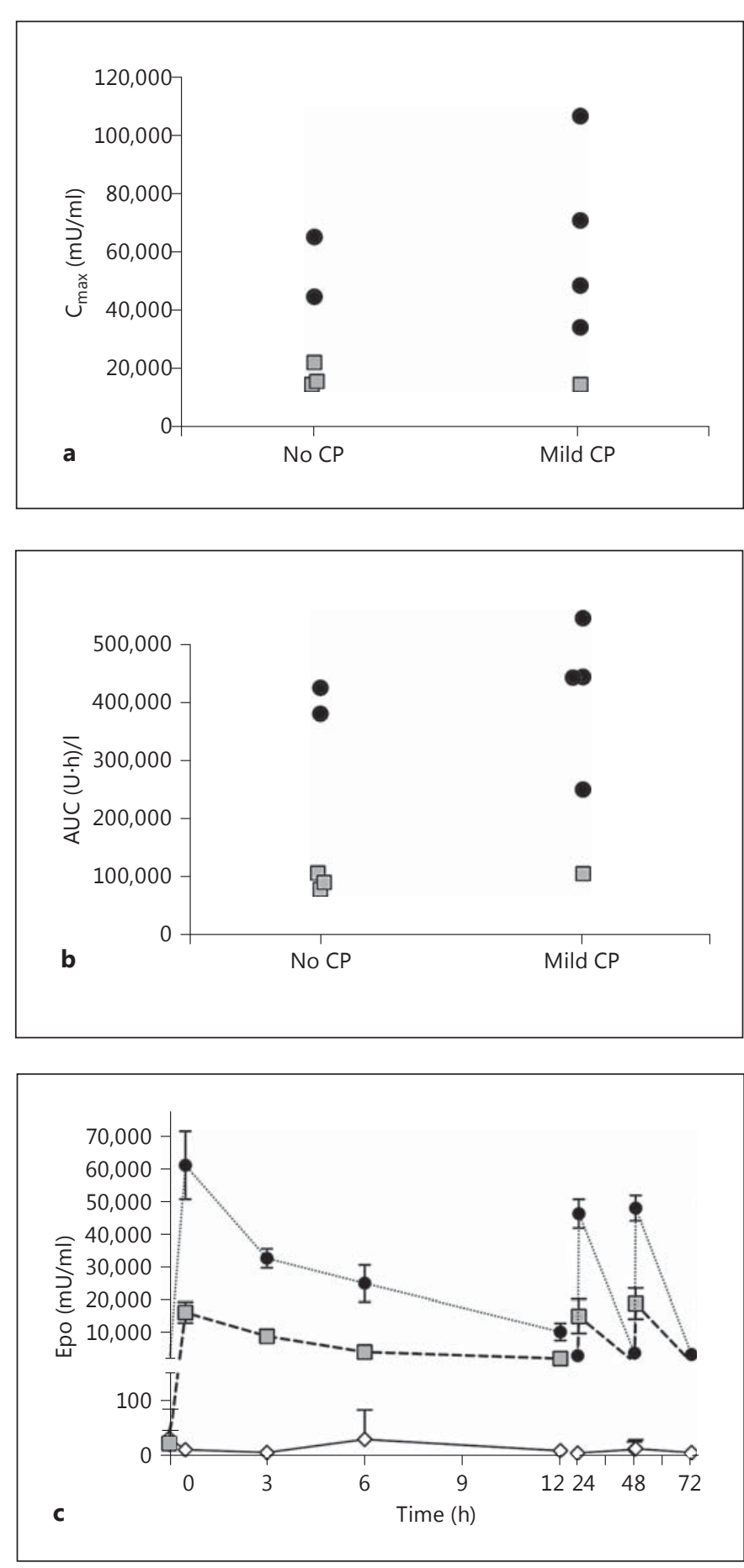

Fig. 8. Pharmacokinetics of Epo in the setting of HT. a Peak Epo concentrations $\left(\mathrm{C}_{\max }\right)$ of the 10 animals treated with $\mathrm{HT}+\mathrm{Epo}$ divided into outcomes of no CP or mild CP. b AUC. c Mean $( \pm$ SEM) plasma concentrations of Epo in the first $72 \mathrm{~h}$. The Epo concentrations of non-Epo-treated asphyxiated animals are shown by diamonds. The pharmacokinetics of high-dose Epo are depicted as circles, while the lower-dose Epo is shown as squares. Epo dosing occurred at 0,24 , and $48 \mathrm{~h}$.
Table 6. Epo pharmacokinetics

\begin{tabular}{lcc}
\hline Epo dose, U/kg & 1,000 & 3,500 \\
Animals, $\mathrm{n}$ & 4 & 6 \\
$\mathrm{AUC},(\mathrm{U} \cdot \mathrm{h}) / \mathrm{l}$ & $94,377 \pm 5,801$ & $413,948 \pm 39,605$ \\
$\mathrm{C}_{\max }, \mathrm{U} / \mathrm{l}$ & $16,290 \pm 1,839$ & $60,996 \pm 10,465$ \\
Clearance, $\mathrm{ml} / \mathrm{h} / \mathrm{kg}$ & $10.7 \pm 0.7$ & $8.6 \pm 0.8$ \\
Half-life, $\mathrm{h}$ & $6.1 \pm 0.6$ & $6.8 \pm 1.0$ \\
MRT, h & $7.2 \pm 0.7$ & $8.1 \pm 0.5$ \\
$\mathrm{~V}_{\mathrm{D}}$ (steady state), $\mathrm{ml} / \mathrm{kg}$ & $76 \pm 4$ & $70 \pm 6.9$ \\
$\mathrm{~V}_{\mathrm{D}}$ (area), ml/kg & $93 \pm 7$ & $85 \pm 15.1$ \\
\hline
\end{tabular}

Data are mean $( \pm$ SEM $)$ values for 2 separate Epo doses. $r E p o=$ Recombinant erythropoietin; $\mathrm{V}_{\mathrm{D}}=$ volume of distribution.

higher-dose Epo, 2 had no CP and 4 had mild CP. Figure $8 \mathrm{a}$ and $\mathrm{b}$ shows the relationship of $\mathrm{C}_{\max }$ and the $\mathrm{AUC}$ to outcome. The $\mathrm{C}_{\max }$ in animals without $\mathrm{CP}$ was 31,889 $\mathrm{mU} / \mathrm{ml}$ with a mean AUC of $215,520 \mathrm{U} \cdot \mathrm{h} / \mathrm{ml}$. In comparison, the $\mathrm{C}_{\max }$ for animals with mild $\mathrm{CP}$ was 54,337 $\mathrm{mU} / \mathrm{ml}$ with a mean AUC of $356,719 \mathrm{U} \cdot \mathrm{h} / \mathrm{ml}$. No animals receiving either dose of Epo in conjunction with HT died or had moderate or severe CP. A summary of all pharmacokinetic parameters is shown in table 6 . As noted previously, Epo dosing results in nonlinear kinetics, with the higher dose resulting in a $>3.5$-fold increase in AUC [18, 32 ]. Of interest, endogenous Epo production was not increased by up to 18 min of UCO (fig. 8c).

\section{Death and $C P$}

In keeping with clinical trials of HT, our primary outcome was the presence of death (prior to planned necropsy) or CP (moderate-severe). Figure 2 shows the number of animals with early death or moderate-severe CP by treatment group. Outcomes for animals that underwent UCO were significantly different than control animal outcomes (Pearson's $\chi^{2}, p=0.046$ ). Treatment changed the outcome of death or moderate-severe CP (Fisher's exact test, $\mathrm{p}=0.46)$. Comparing the UCO saline and combined $\mathrm{HT}+\mathrm{Epo}$ animals gave a relative risk reduction of 0.911 ( $95 \%$ CI -0.429 to 0.994 ), an absolute risk reduction of 0.395 (95\% CI 0.072-0.635), and a number needed to treat of 2 (95\% CI $2-14)$.

\section{Discussion}

In agreement with our prior report [15], 15-18 min of UCO in M. nemestrina produces features that accurately model human perinatal asphyxia, including an abnormal 
physical exam, acidosis, elevated lactate, large base deficits, and Apgar scores that are all comparable to data from human infants enrolled into studies of moderate to severe HIE. Because HT is now the standard of care for the treatment of neonatal HIE [3], the safety and efficacy of new therapies for HIE must be evaluated in concert with HT. This study is the first to evaluate the safety and efficacy of Epo for perinatal asphyxia in combination with HT therapy in primates. The major findings of this study are that, although $72 \mathrm{~h}$ of $\mathrm{HT}$ alone did not reduce the risk of death or moderate-severe CP after UCO, HT combined with 4 doses of Epo decreased the risk of death or moderate-severe $\mathrm{CP}$ to $0 \%$ and preserved normal motor functions. The improvements in motor function are consistent with the finding that combined HT+Epo therapy also preserved cerebellar growth.

The optimal dose and regimen for human Epo neuroprotection is still not known. During the course of this study, we observed that peak Epo concentrations in hypothermic neonatal primates given $2,500 \mathrm{U} / \mathrm{kg}$ were $25 \%$ greater than expected when compared to data from normothermic infants given 2,500 U/kg [12] and, therefore, we lowered the Epo dose to $1,000 \mathrm{U} / \mathrm{kg}$ as a safety precaution. At $1,000 \mathrm{U} / \mathrm{kg}$, the pharmacokinetic parameters obtained from hypothermic primates $\left(C_{\max } \sim 16,000 \mathrm{U} / \mathrm{l}\right.$, AUC 94,000) were comparable to those obtained from normothermic human neonates $\left(\mathrm{C}_{\max } \sim 14,000 \mathrm{U} / \mathrm{l}\right.$, AUC $\sim 81,000)[18,32]$. This dose also results in pharmacokinetic parameters similar to those obtained with 5,000 U/ $\mathrm{kg}$ in rats $\left(\mathrm{C}_{\max } 6,000-10,000 \mathrm{U} / \mathrm{l}\right.$, AUC 120,000-140,000) [33]. Collectively, given the evidence in rodent models that $5,000 \mathrm{U} / \mathrm{kg}$ produces neuroprotection [13] and that multiple injections and late 1-week dosing are most effective [34-36], and given that no harmful drug effects have been noted clinically, we are satisfied that repeated 1,000 $\mathrm{U} / \mathrm{kg}$ i.v. Epo is a safe and effective dose, suitable for future neuroprotection studies.

Several minor observations about the model deserve comment. The initial $\mathrm{pH}$ of the control animals was lower than what would be considered normal in humans, but it quickly normalized. Perhaps the lower $\mathrm{pH}$ is secondary to surgical delivery; general anesthesia or umbilical catheter placement produce brief $\mathrm{HI}$ and subsequent mild acidosis. As seen previously [15], UCO slightly reduced the growth of animals despite nutritional adjustments and it is possible that delayed somatic growth influenced neurodevelopmental outcomes. Also, it is interesting to note that endogenous Epo concentrations were not increased in control animals or in animals exposed to 15-18 min of UCO. Apparently, this duration of UCO is insufficient

Epo and HT Treatment in Perinatal Asphyxia to acutely induce HIF-1 and elevate endogenous Epo release. The lack of an endogenous neonatal response strengthens the rationale for early use of exogenous Epo in neonates after HI.

The DTI findings in this study changed over time after UCO, consistent with pseudonormalization as brain injury evolves [37]. Mode of anisotropy correlated with HI injury within the first $24 \mathrm{~h}$, and we speculate that this index might be interesting as an early diagnostic biomarker of HIE. HT affected the natural progression of DTI changes after HIE. HT+Epo animals tended to have DTI results most similar to those of the controls. The elevated T2 signal in UCO saline animals is similar to the diffuse excessive high-signal intensity (DEHSI) seen in preterm infants; however, the neurodevelopmental outcomes of DEHSI are currently debated [38, 39].

The optimal timing of MRI following injury is variable, depending on whether maximizing sensitivity or specificity is the goal. The known timing of injury in this model provides an opportunity for further delineation of the best practice for timing of MRI as the brain injury evolves over time. MRS has been used to demonstrate injury to the brain during $\mathrm{HI}[40,41]$. We expected to see changes in several metabolites, especially the NAA/lactate ratio, but the only differences between controls and $\mathrm{UCO}$ were the NAA/creatine ratio in the first $72 \mathrm{~h}$ and GABA at 9 months. However, HT and HT+EPO decreased the amount of choline and resulted in better ratios of choline/creatine and NAA/choline. Increased choline levels have been correlated with an increased risk of mortality following HIE [42]. HT+EPO treatment had no deaths and had the lowest choline levels. Choline may be a biomarker of response to treatment and/or a prognostic biomarker. We speculate that choline might be used to determine the length of HT to improve outcomes.

Cerebellar hypoplasia is seen in human infants after HIE [43]. UCO saline decreased the rate of growth in the cerebellum, and treatment with HT+Epo normalized cerebellar growth. The motor problems associated with cerebellar abnormalities are well documented, but there is mounting evidence that the cerebellum is also involved in cognitive performance and social interactions $[44,45]$. Poor neurocognitive outcomes of cerebellar injury/hypoplasia are increasingly being seen in preterm infants without cortical injuries [46]. Social interaction is impaired in humans with autism, and autopsy reports show that 95\% of autistic children have hypoplastic cerebella [47]. While some of the animals that underwent UCO manifested autistic-like repetitive behaviors like self-clasping and rocking, no formal testing was done in this cohort. 
This model of UCO has several strengths. Brain development and complexity are similar to those in humans, allowing for complex neurocognitive testing over time [48]. This study measured developmental indices until 9 months of age, which is comparable to 3 years of human development. The clinical and laboratory findings of asphyxiated animals are very similar to those in humans with moderate to severe HIE. Unlike clinical scenarios in human neonates, however, the timing and severity of the initial injury are known in this model, allowing for uniform initiation of treatments across groups [49-52]. This allows for detection of biomarkers that differentiate the timing and severity of injury.

Limitations of this study include the small number of animals in each group, the refinement of dosing regimens (discussed above), and the change from 15 to $18 \mathrm{~min}$ of UCO. This increase in UCO duration was effected because, as developmental and long-term MRI data were collected, it became apparent that $15 \mathrm{~min}$ of UCO was insufficient to reliably produce the significant disability and lasting brain injury needed to test neuroprotective strategies. The repeated developmental testing may also have served as unintended physical therapy, fostering improved outcomes. Work with nonhuman primates requires teams of clinicians and technicians, sophisticated diagnostic procedures, intensive 24-hour care and longitudinal behavioral testing, so large studies can be prohib- itively expensive. Despite the small number of animals, we are confident that the data presented is informative. Like their human counterparts, these animals exhibit variability in the degree of brain injury sustained, providing an excellent opportunity to identify potential biomarkers of the severity of brain injury, response to therapy, and prognosis.

In conclusion, HT+Epo improved survival without moderate-severe $\mathrm{CP}$, preserved cerebellar growth rates, and improved many neurocognitive behavioral scores after perinatal asphyxia. There were no adverse events attributable to Epo, suggesting that Epo use is safe in the setting of HIE and HT. This translational study sets the stage for further studies of HT+Epo in human neonates with HIE. Future treatment for HIE will likely be multimodal, with accumulating data advocating that Epo be included as one of these treatments.

\section{Acknowledgments}

We thank Sarah Ramelli, Kelly Ledbetter, Marianne Bricker, Brittany Baker, Gerard Wallace, and Nazila Dabestani for their animal care work, and Olivia Janson and Henry Smelser for technical assistance. This study was supported by the US NIH/Eunice Kennedy Shriver National Institute of Child Health and Human Development (R01-HD-52820-01A2 and R01-HD-52820-01A3).

\section{References}

1 Kurinczuk JJ, White-Koning M, and Badawi $\mathrm{N}$ : Epidemiology of neonatal encephalopathy and hypoxic-ischaemic encephalopathy. Early Hum Dev 2010;86:329-338.

-2 Black RE, Cousens S, Johnson HL, Lawn JE, Rudan I, Bassani DG, Jha P, Campbell H, Walker CF, Cibulskis R, Eisele T, Liu L, Mathers C: Global, regional, and national causes of child mortality in 2008: a systematic analysis. Lancet 2010;375:1969-1987.

-3 Edwards AD, Brocklehurst P, Gunn AJ, Halliday H, Juszczak E, Levene M, Strohm B, Thoresen $\mathrm{M}$, Whitelaw A, and Azzopardi D: Neurological outcomes at 18 months of age after moderate hypothermia for perinatal hypoxic ischaemic encephalopathy: synthesis and meta-analysis of trial data. BMJ 2010;340:c363.

-4 Tagin MA, Woolcott CG, Vincer MJ, Whyte RK, Stinson DA: Hypothermia for neonatal hypoxic ischemic encephalopathy: an updated systematic review and meta-analysis. Arch Pediatr Adolesc Med 2012;166:558-566.

5 Volpe JJ: Brain injury in premature infants: a complex amalgam of destructive and developmental disturbances. Lancet Neurol 2009; 8:110-124.
6 Rutherford MA, Pennock JM, Schwieso JE, Cowan FM, Dubowitz LM: Hypoxic ischaemic encephalopathy: early magnetic resonance imaging findings and their evolution. Neuropediatrics 1995;26:183-191.

7 Ferriero DM: Neonatal brain injury. N Engl J Med 2004;351:1985-1995.

8 Gunn AJ, Gunn TR: The 'pharmacology' of neuronal rescue with cerebral hypothermia. Early Hum Dev 1998;53:19-35.

$\checkmark 9$ Gonzalez FF, Ferriero DM: Therapeutics for neonatal brain injury. Pharmacol Ther 2008; 120:43-53.

10 Yu L, Derrick M, Ji H, Silverman RB, Whitsett J, Vasquez-Vivar J, Tan S: Neuronal nitric oxide synthase inhibition prevents cerebral palsy following hypoxia-ischemia in fetal rabbits: comparison between JI-8 and 7-nitroindazole. Dev Neurosci 2011;33:312-319.

11 Xiong M, Chen LX, Ma SM, Yang Y, Zhou WH: Short-term effects of hypothermia on axonal injury, preoligodendrocyte accumulation and oligodendrocyte myelination after hypoxia-ischemia in the hippocampus of immature rat brain. Dev Neurosci 2013;35:1727.
12 Askalan R, Wang C, Shi H, Armstrong E, Yager JY: The effect of postischemic hypothermia on apoptotic cell death in the neonatal rat brain. Dev Neurosci 2011;33:320-329.

13 van der Kooij MA, Groenendaal F, Kavelaars A, Heijnen CJ, van Bel F: Neuroprotective properties and mechanisms of erythropoietin in in vitro and in vivo experimental models for hypoxia/ischemia. Brain Res Rev 2008;59:22-33.

14 McPherson RJ, Juul SE: Erythropoietin for infants with hypoxic-ischemic encephalopathy. Curr Opin Pediatr 2010;22:139-145.

$\checkmark 15$ Jacobson Misbe EN, Richards TL, McPherson RJ, Burbacher TM, Juul SE: Perinatal asphyxia in a nonhuman primate model. Dev Neurosci 2011;33:210-221.

16 Nijboer CH, Kavelaars A, van Bel F, Heijnen CJ, Groenendaal F: Gender-dependent pathways of hypoxia-ischemia-induced cell death and neuroprotection in the immature $\mathrm{P} 3$ rat. Dev Neurosci 2007;29:385-392.

17 Juul SE, Aylward E, Richards T, McPherson RJ, Kuratani J, Burbacher TM: Prenatal cord clamping in newborn Macaca nemestrina: a model of perinatal asphyxia. Dev Neurosci 2007;29:311-320. 
18 Juul SE, McPherson RJ, Bauer LA, Ledbetter KJ, Gleason CA, Mayock DE: A phase I/II trial of high-dose erythropoietin in extremely low birth weight infants: pharmacokinetics and safety. Pediatrics 2008;122:383-391.

-19 Ashworth B: Preliminary trial of carisoprodol in multiple sclerosis. Practitioner 1964;192: 540-542.

-20 Tam EWY, Miller SP, Studholme C, Chau V, Glidden D, Poskitt KJ, Ferriero DM, Barkovich AJ: Differential effects of intraventricular hemorrhage and white matter injury on preterm cerebellar growth. J Pediatr 2011;158: 366-371.

-21 Smith SM, Jenkinson M, Johansen-Berg H, Rueckert D, Nichols TE, Mackay CE, Watkins KE, Ciccarelli O, Cader MZ, Matthews PM, Behrens TEJ: Tract-based spatial statistics: voxelwise analysis of multi-subject diffusion data. Neuroimage 2006;31:1487-1505.

-22 Smith SM, Jenkinson M, Woolrich MW, Beckmann CF, Behrens TEJ, Johansen-Berg H, Bannister PR, De Luca M, Drobnjak I, Flitney DE, Niazy RK, Saunders J, Vickers J, Zhang Y, De Stefano N, Brady JM, Matthews PM: Advances in functional and structural MR image analysis and implementation as FSL. Neuroimage 2004;23(suppl 1):S208S219.

23 Smith SM: Fast robust automated brain extraction. Hum Brain Mapp 2002;17:143-155.

24 Andersson JLR, Jenkinson M, Smith S: Nonlinear optimisation: FMRIB technical report TR07JA1. 2007. www.fmrib.ox.ac.uk/analysis/techrep.

25 Andersson JLR, Jenkinson M, Smith S: Nonlinear registration, aka Spatial normalisation: FMRIB technical report TR07JA2. 2007. www.fmrib.ox.ac.uk/analysis/techrep.

26 Rueckert D, Sonoda LI, Hayes C, Hill DL, Leach MO, Hawkes DJ: Nonrigid registration using free-form deformations: application to breast MR images. IEEE Trans Med Imaging 1999; 18:712-721.

27 Provencher SW: Automatic quantitation of localized in vivo $1 \mathrm{H}$ spectra with LCModel. NMR Biomed 2001;14:260-264.

-28 Provencher SW: Estimation of metabolite concentrations from localized in vivo proton NMR spectra. Magn Reson Med 1993;30: 672-679.

-29 Beckstrom AC, Humston EM, Snyder LR, Synovec RE, Juul SE: Application of comprehensive two-dimensional gas chromatography with time-of-flight mass spectrometry method to identify potential biomarkers of perinatal asphyxia in a non-human primate model. J Chromatogr A 2011;1218:18991906.

30 Burbacher TM, Grant KS: Measuring infant memory: utility of the visual paired-comparison test paradigm for studies in developmental neurotoxicology. Neurotoxicol Teratol 2012;34:473-480.
31 Douaud G, Jbabdi S, Behrens TEJ, Menke RA, Gass A, Monsch AU, Rao A, Whitcher B, Kindlmann G, Matthews PM, Smith S: DTI measures in crossing-fibre areas: increased diffusion anisotropy reveals early white matter alteration in MCI and mild Alzheimer's disease. Neuroimage 2011;55:880-890.

32 Wu YW, Bauer LA, Ballard RA, Ferriero DM, Glidden DV, Mayock DE, Chang T, Durand DJ, Song D, Bonifacio SL, Gonzalez FF, Glass HC, Juul SE: Erythropoietin for neuroprotection in neonatal encephalopathy: safety and pharmacokinetics. Pediatrics 2012;130:683691.

33 Slusarski JD, McPherson RJ, Wallace GN, Juul SE: High-dose erythropoietin does not exacerbate retinopathy of prematurity in rats. Pediatr Res 2009;66:625-630.

34 Kellert BA, McPherson RJ, Juul SE: A comparison of high-dose recombinant erythropoietin treatment regimens in brain-injured neonatal rats. Pediatr Res 2007;61:451-455.

35 Martinez-Salamanca JI, Rao S, Ramanathan R, Gonzalez J, Mandhani A, Yang X, Tu J, Vaughan ED, Tewari A: Nerve advancement with end-to-end reconstruction after partial neurovascular bundle resection: a feasibility study. J Endourol 2007;21:830-835.

-36 Brown MS, Eichorst D, Lala-Black B, Gonzalez R: Higher cumulative doses of erythropoietin and developmental outcomes in preterm infants. Pediatrics 2009;124:e681-e687.

-37 Mac Donald CL, Dikranian K, Bayly P, Holtzman D, Brody D: Diffusion tensor imaging reliably detects experimental traumatic axonal injury and indicates approximate time of injury. J Neurosci 2007;27:11869-11876.

- 38 Jeon TY, Kim JH, Yoo S-Y, Eo H, Kwon J-Y, Lee J, Lee M, Chang YS, Park WS: Neurodevelopmental outcomes in preterm infants: comparison of infants with and without diffuse excessive high signal intensity on MR images at near-term-equivalent age. Radiology 2012;263:518-526.

39 Dyet LE, Kennea N, Counsell SJ, Maalouf EF, Ajayi-Obe M, Duggan PJ, Harrison M, Allsop JM, Hajnal J, Herlihy AH, Edwards B, Laroche S, Cowan FM, Rutherford MA, Edwards AD: Natural history of brain lesions in extremely preterm infants studied with serial magnetic resonance imaging from birth and neurodevelopmental assessment. Pediatrics 2006;118:536-548.

40 Cappellini M, Rapisardi G, Cioni ML, Fonda C: Acute hypoxic encephalopathy in the fullterm newborn: correlation between magnetic resonance spectroscopy and neurological evaluation at short and long term. Radiol Med 2002;104:332-340.

41 Maneru C, Junque C, Bargallo N, Olondo M, Botet F, Tallada M, Guardia J, Mercader JM: (1)H-MR spectroscopy is sensitive to subtle effects of perinatal asphyxia. Neurology 2001; 57:1115-1118.
42 Doormaal P, Meiners L, Horst H, Veere C, Sijens P: The prognostic value of multivoxel magnetic resonance spectroscopy determined metabolite levels in white and grey matter brain tissue for adverse outcome in term newborns following perinatal asphyxia. Eur Radiol 2012;22:772-778.

43 Le Strange E, Saeed N, Cowan FM, Edwards $\mathrm{AD}$, Rutherford MA: MR imaging quantification of cerebellar growth following hypoxicischemic injury to the neonatal brain. Am J Neuroradiol 2004;25:463-468.

44 Volpe JJ: Cerebellum of the premature infant: rapidly developing, vulnerable, clinically important. J Child Neurol 2009;24:1085-1104.

45 Levisohn L, Cronin-Golomb A, Schmahmann JD: Neuropsychological consequences of cerebellar tumour resection in children: cerebellar cognitive affective syndrome in a paediatric population. Brain 2000;123:10411050.

46 Limperopoulos C, Bassan H, Gauvreau K, Robertson RL, Sullivan NR, Benson CB, Avery L, Stewart J, MD JSS, Ringer SA, Volpe JJ, duPlessis AJ: Does cerebellar injury in premature infants contribute to the high prevalence of long-term cognitive, learning, and behavioral disability in survivors? Pediatrics 2007; 120:584-593.

47 Allen G, Courchesne E: Differential effects of developmental cerebellar abnormality on cognitive and motor functions in the cerebellum: an fMRI study of autism. Am J Psychiatry 2003; 160:262-273.

48 Burbacher TM, Grant KS: Methods for studying nonhuman primates in neurobehavioral toxicology and teratology. Neurotoxicol Teratol 2000;22:475-486.

49 Azzopardi DV, Strohm B, Edwards AD, Dyet L, Halliday HL, Juszczak E, Kapellou O, Levene M, Marlow N, Porter E, Thoresen M, Whitelaw A, Brocklehurst P: Moderate hypothermia to treat perinatal asphyxial encephalopathy. N Engl J Med 2009;361:1349-1358.

50 Gluckman PD, Wyatt JS, Azzopardi D, Ballard R, Edwards AD, Ferriero DM, Polin RA, Robertson CM, Thoresen M, Whitelaw A, Gunn AJ: Selective head cooling with mild systemic hypothermia after neonatal encephalopathy: multicentre randomised trial. Lancet 2005;365:663-670

51 Perlman JM: Summary proceedings from the neurology group on hypoxic-ischemic encephalopathy. Pediatrics 2006;117:S28-S33.

52 Shankaran S, Laptook AR, Ehrenkranz RA, Tyson JE, McDonald SA, Donovan EF, Fanaroff AA, Poole WK, Wright LL, Higgins RD, Finer NN, Carlo WA, Duara S, Oh W, Cotten CM, Stevenson DK, Stoll BJ, Lemons JA, Guillet R, Jobe AH: Whole-body hypothermia for neonates with hypoxic-ischemic encephalopathy. N Engl J Med 2005;353:1574-1584. 